\title{
Prevalence of disturbed eating behavior and associated symptoms of anxiety and depression among adult males and females with type 1 diabetes
}

\author{
Line Wisting ${ }^{1,2^{*}}$, Torild Skrivarhaug ${ }^{2,3,4,5}$, Knut Dahl-Jørgensen ${ }^{2,3,4,5}$ and $\varnothing y v i n d ~ R \varnothing^{1,6}$
}

\begin{abstract}
Background: The increased prevalence of disturbed eating behaviors (DEB), depression, and anxiety in type 1 diabetes (T1D) is generally well established; however the majority of existing research to date has focused on female adolescents and young adults. Data on males and older females is scarce. The aim of this study was to assess prevalence of DEB and symptoms of depression and anxiety among adult males and females with type 1 diabetes, to investigate differences between individuals scoring below and above the cut-off on psychopathology, and to examine patterns of eating disorder psychopathology by age and weight.
\end{abstract}

Methods: A total of 282 adults with type 1 diabetes aged 18-79 years participated in the study. Measures included the Diabetes Eating Problem Survey - Revised (DEPS-R), the Hospital Anxiety and Depression Scale (HADS), and clinical data from the Norwegian Quality Improvement of Laboratory Examinations (NOKLUS) system.

Results: A total of $20.3 \%$ of the whole sample (13.3\% among males and $24.8 \%$ among females) scored above the DEPS-R cut-off score for DEB. As for depression and anxiety, the prevalence in the whole sample was $6.2 \%$ and $19.0 \%$, respectively. The prevalence was generally higher in females than males across all psychopathology measures. HbA1c was significantly associated with the DEPS-R total score $(p<.01)$ among females, but not with depression and anxiety. Mean DEPS-R score decreased with increasing age, and when our previous reported data from children and adolescents are included, a peak prevalence in DEB in adolescence and young adult age is demonstrated.

Conclusions: The results of this study point to the need for increased awareness of psychological comorbidity among adults with type 1 diabetes, in particular young adult females. Screening is recommended to secure early detection and subsequent intervention for these individuals.

\section{Plain English summary}

Although increased rates of disturbed eating behaviors (DEB), depression, and anxiety in type 1 diabetes (T1D) are generally reported, data on males and older females is lacking. This study examined frequency of DEB, depression, and anxiety among 282 adult males and females with T1D across a wide age span. Approximately one-fifth of the participants (and a quarter of all females)

\footnotetext{
* Correspondence: line.wisting@ous-hf.no

${ }^{1}$ Regional Department for Eating Disorders, Division of Mental Health and Addiction, Oslo University Hospital, P.O. Box 4956 Nydalen, N-0424 Oslo, Norway

${ }^{2}$ Oslo Diabetes Research Centre, P.O. Box 4956 Nydalen, N-0424 Oslo, Norway Full list of author information is available at the end of the article
}

scored above cut-off for DEB, $6.2 \%$ scored above cut-off for depression, and $19.0 \%$ for anxiety. The prevalence was generally higher in females than males across all psychopathology. HbA1c (a measure of long term blood glucose levels) was significantly associated with DEB, but not with depression and anxiety. Symptoms of DEB decreased with increasing age, and when our previous reported data from children and adolescents are included, a peak in levels of DEB during late adolescence and young adulthood was observed. Therefore, increased awareness of psychological comorbidity among adults with T1D is warranted, especially among young adult females.

(c) The Author(s). 2018 Open Access This article is distributed under the terms of the Creative Commons Attribution 4.0 International License (http://creativecommons.org/licenses/by/4.0/), which permits unrestricted use, distribution, and reproduction in any medium, provided you give appropriate credit to the original author(s) and the source, provide a link to the Creative Commons license, and indicate if changes were made. The Creative Commons Public Domain Dedication waiver (http://creativecommons.org/publicdomain/zero/1.0/) applies to the data made available in this article, unless otherwise stated. 


\section{Background}

Eating disorders are characterized by a restricted or chaotic food intake, a morbid preoccupation with food, weight, and shape and a distorted body image (1). The Diagnostic and Statistical Manual of Mental Disorders (DSM-5) defines the eating disorders anorexia nervosa, bulimia nervosa, binge eating disorder, other specified feeding and eating disorders and unspecified feeding and eating disorders [1]. Additionally, there are reports of some lower degree eating disturbances which do not meet frequency- or severity criteria for a formal eating disorder diagnosis as defined by diagnostic manuals such as the DSM-5. These disturbances have been defined as disturbed eating behaviors (DEB) [2], a term which will be used to describe all eating disorder psychopathology in this study.

Individuals with type T1D have been found to be at risk of developing DEB, with prevalence rates in T1D reported to be 2-3 times higher in individuals with T1D compared to healthy controls [3-5]. Possible contributing factors include the weight loss accompanied with T1D onset, the weight gain subsequent to diagnosis and initiation of intensive insulin therapy [6], and the required monitoring of food intake in order to plan insulin dosing. Finally, the availability of insulin omission as a unique, T1D-specific compensatory behavior, reported in up to $37 \%$ of females with T1D [7], is considered a potential risk factor for developing DEB in T1D. This comorbidity is associated with accelerated onset of T1D complications and increased rates of mortality compared with individuals with T1D without disturbed eating $[7,8]$.

The eating disorder literature has generally focused the most on adolescent and young adult populations, but increased attention has acknowledged the presence of eating disorder psychopathology also in older samples [9]. It is likely that this will be reflected in adult T1D samples as well. Although the increased prevalence of DEB in T1D is generally well established, a majority of existing research to date has focused on female adolescents and young adults $[10,11]$. There is a lack of knowledge about levels of DEB among males and older females with T1D. It is known that risk of DEB varies with age and weight in the general population and among children and adolescents with T1D. It is unclear whether this is true for adults with T1D.

Mood and anxiety disorders have been found to be the most common psychiatric comorbidity in eating disorder populations [12]. Similarly, an array of research has documented increased prevalence of depression and anxiety in individuals with T1D compared to healthy controls $[10,13,14]$. Furthermore, although a majority of the literature reports positive correlations between psychopathology and poor metabolic control [15-19], other studies have yielded mixed support for these associations [20-23].
This study aimed to i) assess the prevalence of DEB and associated symptoms of depression and anxiety among adult males and females with T1D; ii) investigate differences between individuals scoring below and above the cut-off on psychopathology, with a specific focus on metabolic control; and iii) examine patterns of eating disorder psychopathology by age and weight.

\section{Methods \\ Design}

This is a cross-sectional design study.

\section{Procedure}

Patients with T1D were recruited from the Norwegian Diabetic Centre (NDC) between February 2016 and October 2017. The NDC is an outpatient clinic for adults (approximately 1300) with T1D, located in Oslo. Patients from Oslo and surrounding areas are referred to the NDC by both general practitioners and hospitals. The NDC is a multidisciplinary clinic organized under the Norwegian Health South-East Authority. Questionnaires were completed as part of a routine T1D consultation at the outpatient clinic. The regional ethics committee approved the study, and written consent was obtained from all participants.

\section{Measures}

The Diabetes Eating Problem Survey - Revised (DEPS-R) [24] is a diabetes-specific screening tool for disturbed eating and consists of 16 items. Responses are scored on a 6-point Likert scale and higher scores indicate greater pathology. A recommended cut-off score of $>=20$ has been empirically established as a threshold indicating the need for further clinical assessment of eating pathology [24]. The DEPS-R has been translated and validated in a Norwegian adolescent sample aged 11-19 years [25].

The Hospital Anxiety and Depression Scale (HADS) [26] was developed to map symptoms of anxiety and depression in patients in treatment of somatic diseases. Somatic symptoms on anxiety and depression are therefore avoided in HADS in order to prevent that somatic illnesses would be misinterpreted as symptoms of anxiety and depression. HADS consists of two subscales, measuring anxiety (HADS-A) and depression (HADS-D), in addition to the total score. The Norwegian version of HADS has previously demonstrated satisfactory psychometric properties [27]. A cut-off score of $\geq 8$ is often used for the two subscales to indicate symptoms of anxiety and/or depression need for further evaluation, whereas a cut-off score of $\geq 11$ is used to indicate a case (i.e. moderate to severe symptoms). T1D is often associated with fear of hypoglycemia, fear of complications, and diabetes distress $[10,17]$, which may lead to elevated scores on the HADS. To minimize the risk of over pathologizing due to 
such diabetes-specific aspects, the current study therefore adopts the cut-off score of 11 to report prevalence of symptoms of depression and anxiety. However, as control data has been carried out using a cut-off of 8 , rates based on this cut-off score will also be briefly reported for comparative purposes.

BMI was calculated based on self-reported weight and height $\left(\mathrm{kg} / \mathrm{m}^{2}\right)$, and further categorized into the following four groups according to the World Health Organization classification scheme [28]: underweight $(\mathrm{BMI}<18.5)$, normal weight (BMI $\geq 18.5-24.9)$, overweight (BMI $\geq 25-29.9$ ), and obese (BMI $\geq 30$ ).

Age was categorized based on the Center for Disease Control and Prevention (CDC) age groupings [29]: 1524 years (youngest person was 18 in the current study), 25-34 years, 35-44 years, 45-54 years, 55-64 years, and $\geq$ 65 years. These age groups are used in previous ED research [30]. Given the relatively low number of participants $>55$ years, the two latter groups were collapsed, yielding a total of five age groups (18-24 years, 25-34 years, 3544 years, $45-54$ years, and 55 years and above).

Clinical data was assessed via the Norwegian Quality Improvement of Laboratory Examinations (NOKLUS) system, and was conducted as part of standard clinical T1D assessment at the Norwegian Diabetic Centre. T1D clinical data include HbA1c, T1D onset, and treatment mode. HbA1c is a measure of long term blood glucose levels and reflects average blood glucose the preceding 8-12 weeks. $\mathrm{HbA} 1 \mathrm{c}$ is used here as a measure of metabolic control. A reasonable $\mathrm{HbA1c}$ target for many nonpregnant adults is $<7.0 \%$ (53 $\mathrm{mmol} / \mathrm{mol}$ ). The providers might reasonably suggest a more stringent HbAlc goals such as $6.5 \%$ ( $48 \mathrm{mmol} / \mathrm{mol}$ ) for selected individual patients if this can be achieved without significant hypoglycemia or other adverse effects of treatment (i.e., polypharmacy) [31].

\section{Data analyses}

Pearson correlations were conducted to investigate associations between variables. In line with Cohen [32], correlations of .10 to .29 were interpreted as small, .30 to .49 as medium and .50 to 1.0 as large. Independent samples t-tests were carried out to investigate group differences. Pearson chi-squares were used for categorical variables. Alpha level was set to $p<.05$. Effect sizes were calculated by means of Cohen's $d$. Following the guidelines by Cohen [32], effect sizes $>0.2$ were interpreted as small, $>0.5$ as medium and $>0.8$ as large. Statistical analyses were conducted using SPSS version 23 (SPSS IBM, NY, USA) [33].

\section{Results}

\section{Participant characteristics}

A total of 282 males and females aged $18-79$ years (60\% females) participated in the study (mean age 42.11; SD: 15.19). Table 1 illustrates sample characteristics. Mean age of T1D onset was 15.14 (SD: 11.18), mean HbA1c was 7.75\% (SD: .91), and mean BMI was 25.96 (SD: 4.13). A total of $56.3 \%$ administered insulin with an insulin pen and $43.3 \%$ with a pump. All patients used basal/bolus insulin treatment, none fixed premixed regimens.

\section{Prevalence of disturbed eating behavior, depression, and anxiety}

A total of $20.3 \%$ of the whole sample scored above the established DEPS-R cut-off score for DEB (Table 2). When split by gender, $13.3 \%$ of the males and $24.8 \%$ of the females scored above the cut-off score. As for depression and anxiety, when using the cut-off score of 11 , the prevalence in the whole sample was $6.2 \%$ and $19.0 \%$, respectively. In males only, the prevalence was $3.6 \%$ for depression and $8.1 \%$ for anxiety. The prevalence was generally higher in females than males across all psychopathology scores, with rates of depression and anxiety at 7.8 and $26.4 \%$.

Prevalence rates for depression and anxiety when using a cut-off score of 8 was also assessed, yielding prevalence rates of $13.8 \%$ and $35.4 \%$ for depression and anxiety for the whole sample. When split by gender, the prevalence of depression and anxiety was $11.8 \%$ and $24.3 \%$ among males and $15.1 \%$ and $42.9 \%$ among females.

The frequency of participants scoring above the cut-off score one more than one of the psychopathology measures (disturbed eating, depression, and anxiety) was

Table 1 Participant characteristics

\begin{tabular}{|c|c|c|c|c|c|}
\hline & All $N=282$ & Males $N=112(40 \%)$ & Females $N=170(60 \%)$ & Sig. level & Effect size \\
\hline Age & $42.11(15.19)$ & $44.57(15.92)$ & $40.47(14.49)$ & .05 & .27 \\
\hline Diabetes onset (years) & $15.14(11.18)$ & $15.43(10.92)$ & $14.94(11.38)$ & ns & - \\
\hline $\mathrm{HbA1c}(\%)$ & $7.75(.91)$ & $7.61(.89)$ & $7.85(.91)$ & ns & - \\
\hline Diabetes duration (years) & $27.09(14.44)$ & $29.14(14.82)$ & $25.71(14.05)$ & ns & - \\
\hline BMI self-report & $25.96(4.13)$ & $26.47(3.82)$ & $25.63(4.30)$ & ns & - \\
\hline Mode of insulin treatment & $\begin{array}{l}\text { 56.3\% pen } \\
43.3 \% \text { pump }\end{array}$ & $\begin{array}{l}\text { 60.9\% pen } \\
\text { 38.0\% pump }\end{array}$ & $\begin{array}{l}\text { 53.4\% pen } \\
\text { 46.6\% pump }\end{array}$ & & \\
\hline
\end{tabular}

Data are mean (SD). Significance level $(p<.001, .01$, and .05$)$ and effect size (ES) estimation (Cohen's $d$ ) is calculated when differences are significant. Ns not statistical significant differences 
Table 2 Prevalence rates of DEB, anxiety, and depression, in adult males and females with T1D, based on a cut-off score for DEB of 20 or more on the DEPS-R, and 11 or more on the HADS subscales anxiety and depression

\begin{tabular}{lllll}
\hline & All & Males & Females & $P$-value \\
\hline DEB & $20.3 \%$ & $13.3 \%$ & $24.8 \%$ & .05 \\
Depression & $6.2 \%$ & $3.6 \%$ & $7.8 \%$ & $\mathrm{~ns}$ \\
Anxiety & $19 \%$ & $8.1 \%$ & $26.4 \%$ & .001 \\
\hline
\end{tabular}

The Chi-square test for independence was used to investigate whether the proportion of individuals scoring above the cut-off scores on the DEPS-R as well as the HAD anxiety and depression subscales, was significant different for males and females

also examined. In the whole sample, a total of $8.5 \%$ (4.8\% of males and $11.0 \%$ of females) had two positive screens (i.e. scored above cut-off for either two of the three measures of psychopathology), whereas $5.4 \%$ (2.9\% males and $7.1 \%$ females) had three positive screens (i.e. scored above the cut-off score for all three measures of psychopathology).

As shown in Table 3, there were no significant differences in metabolic control between patients with versus without DEB, depression, or anxiety. As for age, BMI, and T1D duration, the results were mixed. There were no significant differences between individuals with no psychopathology (zero positive screens) and two positive screens. When comparing individuals with no positive screens versus three positive screens, a statistical significant difference found was in age, demonstrating that individuals with three positive screens were significantly younger than individuals with no positive screens (31.9 years (10.8) versus 43.9 years (15.9), $p<01$ ).

Mean DEPS-R score was 13.83 (9.16) for the total population, 11.18 (7.80) for males, and 15.57 (9.59) for females $(p<.001$, effect size -.50), indicating higher levels of eating disorder psychopathology among females. Table 4 shows the DEPS- $R$ mean scores among males and females according to different categories of age and weight. Figures 1 and 2 further illustrate the distribution of eating disorder psychopathology by the different age and weight groups. The DEPS-R mean score decreased steadily by age among females, whereas the trend for males were more mixed. As for weight, the DEPS-R mean score increased by increasing weight category for both males and females. Mean score for the HADS depression subscale in the total sample, males, and females was 3.75 (3.61), 3.53 (3.35), and 3.90 (3.77), respectively, with no significant difference between males and females. For anxiety, the mean scores for the whole sample was 6.39 (4.27), and 5.12 (3.67) and 7.26 (4.44) for males and females, respectively.

\section{Associations}

Table 5 demonstrates associations between eating disorder psychopathology, depression, anxiety, age, BMI, and HbA1c. Significant associations were found between symptoms of eating disorder psychopathology, depression, and anxiety, with correlation coefficients ranging from $.39(p<.001)$ to $.61(p<.001)$ among males, and $.47(p<.001)$ to $.68(p$ $<.001)$ among females. Furthermore, HbA1c was significantly associated with the DEPS-R total score among females $(.27, p<.01)$, but not among males. However, HbA1c was not significantly correlated with the subscale scores of depression and anxiety in neither males nor females. BMI was significantly and positively correlated with eating the DEPS-R total score $(.33, p<.001)$ and depression $(.30, p$ $<.001$ ) among females, but not with anxiety. Among males, BMI was only significantly associated with the DEPS-R total score $(.35, p<.001)$, but not with scores of depression or anxiety. Finally, age was significantly and negatively associated with both the DEPS-R and HADS anxiety total scores among females $(-.32, p<.001$ and $-.24, p<.01$, respectively), with lower levels of anxiety and eating disorder psychopathology with higher age (age was not significantly associated with depression). Age was not significantly associated with any of the psychopathology scores among males.

\section{Discussion}

This study reported the prevalence of DEB among adult males (13.3\%) and females (24.8\%) with T1D. Level of eating disorder psychopathology decreased with increasing age among females. Furthermore, symptoms of

Table 3 Comparison of participants with and without disturbed eating behavior (below/above the DEPS-R cut-off of $\geq 20$ ), depression (below/above the HAD depression cut-off score $\geq 11$ ), and anxiety (below/above the HAD anxiety cut-off score $\geq 11$ )

\begin{tabular}{|c|c|c|c|c|c|c|c|c|c|c|c|c|c|c|c|c|c|c|c|c|}
\hline & $\begin{array}{l}\text { DEB } \\
-\end{array}$ & $\begin{array}{l}\text { DEB } \\
+\end{array}$ & $\begin{array}{l}\text { Sig. } \\
\text { level }\end{array}$ & ES & $\begin{array}{l}\text { Depr } \\
\text { - }\end{array}$ & $\begin{array}{l}\text { Depr } \\
+\end{array}$ & $\begin{array}{l}\text { Sig. } \\
\text { level }\end{array}$ & ES & Anx - & $\begin{array}{l}\text { Anx } \\
+\end{array}$ & $\begin{array}{l}\text { Sig. } \\
\text { level }\end{array}$ & ES & $\begin{array}{l}\text { No pos } \\
\text { screens }\end{array}$ & $\begin{array}{l}2 \text { pos } \\
\text { screens }\end{array}$ & Sig.level & ES & $\begin{array}{l}\text { No pos } \\
\text { screens }\end{array}$ & $\begin{array}{l}3 \text { pos } \\
\text { screens }\end{array}$ & $\begin{array}{l}\text { Sig. } \\
\text { level }\end{array}$ & ES \\
\hline $\begin{array}{l}\mathrm{HbA1c} \\
(\%)\end{array}$ & $\begin{array}{l}7.7 \\
(.9)\end{array}$ & $\begin{array}{l}8.0 \\
(.9)\end{array}$ & ns & - & $\begin{array}{l}7.7 \\
(.9)\end{array}$ & $\begin{array}{l}8.0 \\
(.8)\end{array}$ & ns & - & $\begin{array}{l}7.7 \\
(.9)\end{array}$ & $\begin{array}{l}7.8 \\
(.8)\end{array}$ & ns & - & $7.7(.9)$ & $7.9(.8)$ & ns & - & $7.7(.9)$ & $7.9(.8)$ & ns & - \\
\hline BMI & $\begin{array}{l}25.5 \\
(3.7)\end{array}$ & $\begin{array}{l}27.7 \\
(4.9)\end{array}$ & .01 & 0.5 & $\begin{array}{l}25.8 \\
(3.8)\end{array}$ & $\begin{array}{l}29.2 \\
(7.1)\end{array}$ & ns & - & $\begin{array}{l}25.9 \\
(3.8)\end{array}$ & $\begin{array}{l}26.6 \\
(5.4)\end{array}$ & ns & - & $\begin{array}{l}25.5 \\
(3.5)\end{array}$ & $\begin{array}{l}26.9 \\
(5.6)\end{array}$ & ns & - & $\begin{array}{l}25.5 \\
(3.5)\end{array}$ & $\begin{array}{l}29.1 \\
(6.5)\end{array}$ & ns & - \\
\hline $\begin{array}{l}\text { T1D } \\
\text { duration }\end{array}$ & $\begin{array}{l}28.4 \\
(14.8)\end{array}$ & $\begin{array}{l}24.0 \\
(12.7)\end{array}$ & .05 & -0.3 & $\begin{array}{l}27.2 \\
(14.6)\end{array}$ & $\begin{array}{l}27.5 \\
(12.6)\end{array}$ & ns & - & $\begin{array}{l}27.8 \\
(14.8)\end{array}$ & $\begin{array}{l}24.8 \\
(13.1)\end{array}$ & ns & - & $\begin{array}{l}28.3 \\
(15.2)\end{array}$ & $\begin{array}{l}31.5 \\
(13.5)\end{array}$ & ns & - & $\begin{array}{l}28.3 \\
(15.2)\end{array}$ & $\begin{array}{l}21.3 \\
(11.0)\end{array}$ & ns & - \\
\hline $\begin{array}{l}\text { Age } \\
\text { (years) }\end{array}$ & $\begin{array}{l}44.1 \\
(15.3)\end{array}$ & $\begin{array}{l}35.4 \\
(12.4)\end{array}$ & .001 & -0.6 & $\begin{array}{l}42.3 \\
(15.4)\end{array}$ & $\begin{array}{l}39.9 \\
(11.3)\end{array}$ & ns & - & $\begin{array}{l}43.1 \\
(15.5)\end{array}$ & $\begin{array}{l}38.3 \\
(13.1)\end{array}$ & .05 & .3 & $\begin{array}{l}43.9 \\
(15.9)\end{array}$ & $\begin{array}{l}43.0 \\
(14.6)\end{array}$ & ns & - & $\begin{array}{l}43.9 \\
(15.9)\end{array}$ & $\begin{array}{l}31.9 \\
(10.8)\end{array}$ & .01 & .9 \\
\hline
\end{tabular}

Data are mean (SD), significance level $(p<.001, .01$, and .05) and effect size (ES) estimation (Cohen's $d$ ) 
Table 4 DEPS-R mean scores in males and females with T1D according to different categories of age and weight

\begin{tabular}{lllll}
\hline & All & Males & Females & Sig. level \\
\hline Age & & & & \\
18-24 years & $16.39(10.4)$ & $10.36(8.8)$ & $19.92(9.7)$ & .01 \\
25-34 years & $16.11(10.5)$ & $11.75(6.7)$ & $17.95(11.4)$ & .05 \\
35-44 years & $15.46(9.9)$ & $14.17(10.3)$ & $16.32(9.7)$ & $\mathrm{ns}$ \\
45-54 years & $12.48(7.1)$ & $9.6(5.5)$ & $14.33(7.5)$ & .05 \\
55-64 years & $10.06(6.9)$ & $10.71(8.5)$ & $9.6(5.5)$ & $\mathrm{ns}$ \\
$\geq 65$ years & $10.00(6.0)$ & $9.7(5.2)$ & $10.42(7.3)$ & $\mathrm{ns}$ \\
BMl & & & & \\
Underweight & $4.50(5.0)$ & - & $4.50(5.0)$ & - \\
Normal weight & $11.89(8.6)$ & $9.55(7.3)$ & $13.20(9.0)$ & .05 \\
Overweight & $13.89(8.3)$ & $10.48(7.1)$ & $16.46(8.3)$ & .001 \\
Obese & $19.94(10.5)$ & $17.53(8.6)$ & $21.84(11.6)$ & $\mathrm{ns}$ \\
\hline
\end{tabular}

data are means (standard deviations)

depression and anxiety were reported, with one fourth of females scoring above cut-off for anxiety. Females had generally higher scores on measures of psychopathology in terms of DEB, depression, and anxiety, than males.

\section{Prevalence of DEB}

The observed gender difference in prevalence of DEB supports previous studies of eating disorder psychopathology, both in diabetes [34, 35] and non-diabetes [36] samples. Furthermore, the prevalence increased by increasing weight, which is comparable to pediatric T1D samples [25, 37-39] as well as the ED literature in general [40]. However, it should be noted that BMI generally increases with age, and the current sample is relatively old compared to many studies of comorbid DEB and T1D. In line with previous research [40], the prevalence of DEB was highest among the young adult females, with decreasing eating disorder psychopathology with older age. This is the opposite trend to what has been reported in child and adolescent samples, where rates of disturbed eating have been found to increase by increasing age [39]. This most likely reflects the peak age of eating disorder onset during late adolescence and early adulthood among females [36]. This peak in DEB during late adolescence and early adulthood is also evident in Fig. 1, illustrating levels of DEB according to different age groups in our previous adolescent sample [39] and the current adult sample. Older adolescents and young adults with T1D is generally found to be in a vulnerable phase as they are in the process of transferring from pediatric to adult health care, indicating lower levels of care and support. Additionally, individuals at this point in life typically move away from their home for the first time [41-43].

\section{Prevalence symptoms of anxiety}

This study found that $8.1 \%$ of males and $26.4 \%$ of females scored above the cut-off score for anxiety at 11 or above (HADS-A). These rates are comparable to those reported by Lloyd et al. [44] among their mixed sample of patients with both T1D and type 2 diabetes (T2D). Using the same cut-off as the current study, a total of $25 \%$ scored above cut-off for moderate to severe symptoms of anxiety. Females tended to report more moderate-severe anxiety than males. There were no significant differences between types of diabetes. Another study used the 8 or above cut-off score on the HADS-A, and found that $22.4 \%$ of the males and $37.2 \%$ of the females had mild symptoms of anxiety. Furthermore, a systematic review of diabetes and anxiety [14] reported prevalence rates ranging from 15 to $27.5 \%$ when using the cut-off score 8 on the HADS-A. As can be expected with the use of a lower cut-off, these rates are somewhat higher than those reported in our study, and in the study by Lloyd et al. [44].

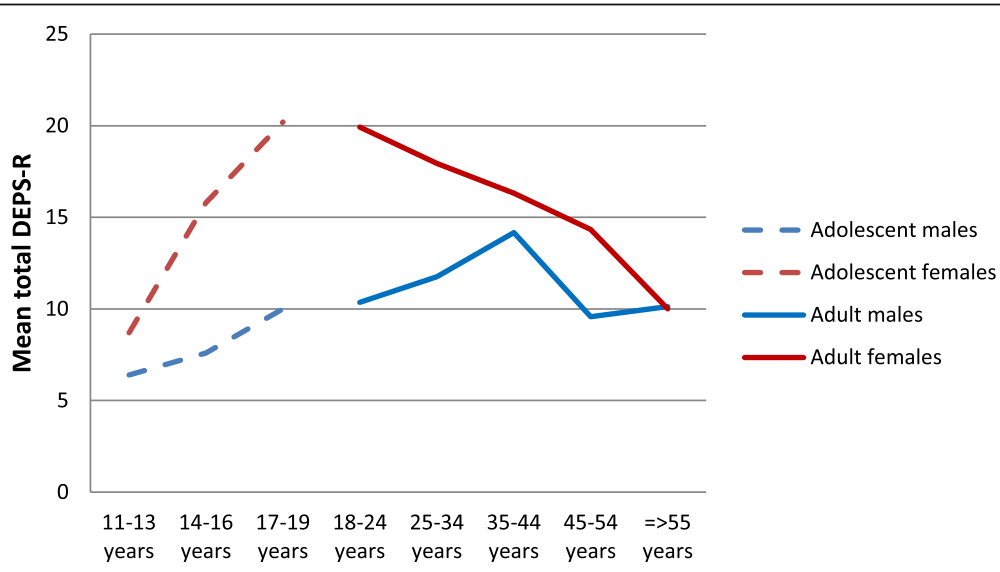

Fig. 1 Mean DEPS-R total score according to age group in the current sample of adult males and females with T1D, as depicted by a solid lineNote: Mean DEPS-R total score according to age group in our previous sample of adolescent males and females with T1D [25] is indicated by a dashed line 


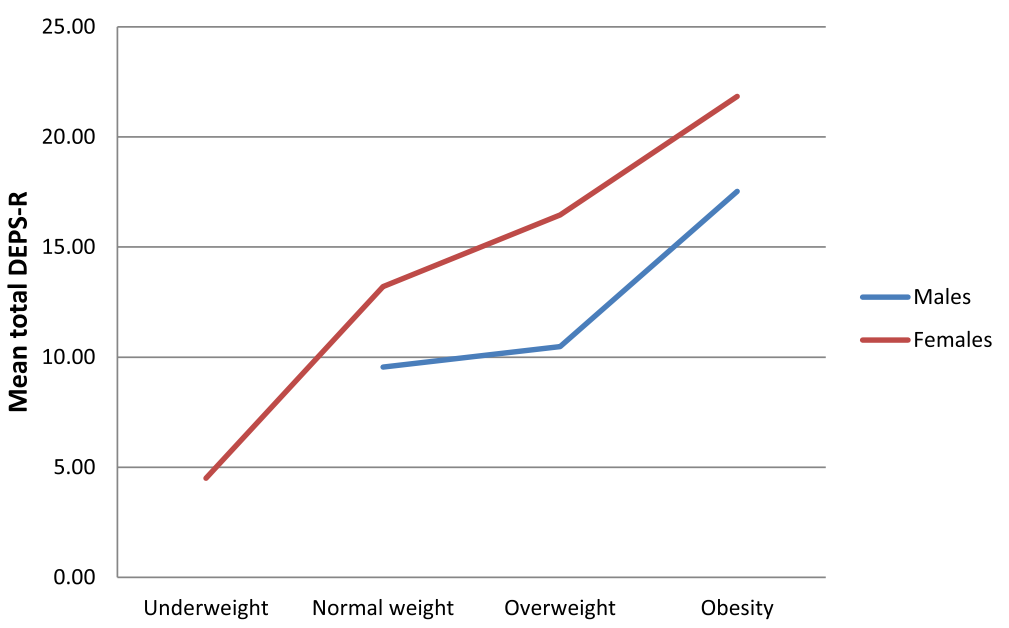

Fig. 2 Mean DEPS-R total score in males and females with T1D by BMI categoryNote: BMI was categorized into the following four groups according to the World Health Organization classification scheme (28): underweight (BMI < 18.5), normal weight (BMI $\geq 18.5-24.9)$, overweight $(\mathrm{BMI} \geq 25-29.9)$, and obese $(\mathrm{BMl} \geq 30)$

The current study did not include a control group to compare rates of anxiety in this T1D population to those of non-diabetes controls. However, a large Norwegian population study (the HUNT 2 study) has been conducted, reporting levels of anxiety in the general population, aged 20-89 years $(N=60.869)$. Bjelland et al. [45] reported that $9.6 \%$ scored above the cut-off score of 8 for anxiety. When using the same cut-off score in our sample of both males and females with T1D, a prevalence of $35.4 \%$ was reported for anxiety. This is much higher than the prevalence reported in the HUNT study, suggesting that levels of anxiety are higher among patients with T1D than non-diabetes controls.

As the HADS is a generic measure, it should be noted that reported symptoms of anxiety in the current study may be driven by diabetes-specific distress. Previously reported diabetes-specific features of anxiety include fear of complications, fear of hypoglycemia, and invasive self-care behaviors such as fear of injections, self-monitoring of blood glucose, and insertion of subcutaneous insulin infusion devices such as an insulin pump [10]. Such illnessspecific aspects may contribute to higher rates of anxiety among patients with diabetes.

\section{Prevalence symptoms of depression}

A total of $11.8 \%$ of the males and $7.8 \%$ of the females scored above the cut-off score for depression (HADS-D) in the present study, indicating moderate to severe symptoms of depression, or "caseness". Lloyd et al. [44], using the same cut-off, found that $8 \%$ of the patients with diabetes scored above the cut-off for depression, thus in line with our study. Knychala et al. [46] used the cut-off score of 8 , and reported prevalence rates of $4.7 \%$ among males and $17.6 \%$ of females with diabetes. Given the lower cut-off, the higher prevalence rates compared to the previous two studies, can be expected. The meta-analysis by Anderson et al. [13], however, reported higher prevalence rates, with rates for elevated depressive symptoms being $21.3 \%$ for adults with T1D. Rates of depressive disorders, as assessed by a diagnostic

Table 5 Associations between psychopathology (disturbed eating, depression, and anxiety), age, BMI, and HbA1C, in adult males (left diagonal) and females (bold, right diagonal) with T1D

\begin{tabular}{|c|c|c|c|c|c|c|c|}
\hline \multirow{2}{*}{\multicolumn{2}{|c|}{ Males }} & \multicolumn{4}{|c|}{ Females } & \multirow[b]{2}{*}{ BMl } & \multirow[b]{2}{*}{$\mathrm{HbA1c}$} \\
\hline & & DEPS-R total & HAD depression & HAD anxiety & Age & & \\
\hline & DEPS-R total & - & $.47^{* * *}$ & $.48^{* * *}$ & $-.32^{* * *}$ & $.33^{* * *}$ & $.27^{* *}$ \\
\hline & HAD depression & $.39 * * *$ & - & $.68^{* * *}$ & ns & $.30 * * *$ & ns \\
\hline & HAD anxiety & $.50^{* * *}$ & $.61^{* * *}$ & - & $-.24^{* *}$ & ns & ns \\
\hline & Age & ns & ns & ns & - & ns & ns \\
\hline & BMl & $.35^{* * *}$ & ns & ns & ns & - & $.19^{*}$ \\
\hline & $\mathrm{HbA1c}$ & ns & ns & ns & $-.24^{*}$ & ns & - \\
\hline
\end{tabular}

data are Pearson correlation coefficients, and significance levels are indicated by ${ }^{*} \mathrm{~s}\left(p<.001^{* * *} ; p<.01^{* *} ; p<.05^{*}\right)$. Ns not significant associations entries in the right diagonale are marked in bold to indicate that they refer to the females of our sample 
interview, ranged from 8 to $15 \%$ in adults with T1D and T2D (no studies investigated rates in samples with T1D only). A systematic review by Roy et al. [47] reported a three-fold increase in prevalence of depression among individuals with T1D compared to those without, with prevalence rates ranging from 5.8 to $43.3 \%$ (range among individuals without diabetes was $2.7 \%$ to $11.4 \%$ ).

As for comparison with Norwegian control data, the prevalence of depression when using the cut-off score of 8 was $4.9 \%$ in the HUNT 2 study [45]. When using the same cut-off in the current study, we found a prevalence of depression at $13.8 \%$, indicating that levels of depression are higher among individuals with T1D than individuals without.

The varying prevalence rates across studies underlines the importance of considering methodological aspects when interpreting reported prevalence rates. It is important to note that reported prevalence rates are highly dependent on the adopted cut-off score, and there are variations in the literature as to which cut-off score is utilized. We chose to adopt the more conservative cut-off 11 to minimize the risk of over pathologizing. The adopted cut-off score is important to take into account when interpreting prevalence rates across studies. Finally, it should be noted that screening measures cannot be used to establish a diagnosis as defined by diagnostic manuals. This can only be done with clinical diagnostic interviews. Screening measures of psychopathology may yield inaccurate estimates, but they are a simple and quick method. Therefore, it is recommended to validate positive screens with an interview.

\section{Above versus below cut-off on psychopathology}

There was no significant difference in HbA1c among patients scoring above versus below the DEPS-R or the HADS depression or anxiety cut-off scores. Eating disorder psychopathology (mean DEPS-R total score) was, however, significantly and positively associated with metabolic control in females, but this was not the case for depression or anxiety. It is not clear why there was no significant difference in HbA1c between individuals scoring above versus below cut-off on the DEPS-R when the association between the DEPS-R total score and HbA1c is significant. One potential reason is that the analysis is less sensitive when the data are dichotomous rather than dimensional. It should also be mentioned that despite the presence of DEB, depression, and anxiety, the HbA1c in the current sample is relatively good. Further, the percentage of patients using an insulin pump is relatively high. These factors might indicate that the patients receive good T1D care within a multidisciplinary team, including psychological health care personnel. The lack of associations between depression/anxiety and metabolic control is in contrast to several other studies [15-18], although not all $[23,48]$. The discrepancies in this regard across studies may be explained by various factors. For example, it has been argued that it has been suggested that distinct profiles of depression exist, which may impact outcome differently [49]. Also, it has been shown that diabetes-specific emotional distress, not depression, is associated with metabolic control [23]. These two concepts are commonly being used interchangeably, despite the fact that they are not overlapping constructs $[49,50]$. An underlying construct of diabetes-specific emotional distress be considered as a core structure to link diabetes-related distress, subclinical depression, elevated depression symptoms, and major depressive disorder [50]. Targeting illness-specific cognitions may be more productive than treatment of general dysphoria in T1D [22].

Although studies have found significant relationships between the HADS scales and metabolic control [44], the lack of significant relationship between anxiety/depression and metabolic control in our study may also be explained by the use of this measure, which was specifically designed for patients within a hospital setting. To avoid false positives, i.e. avoid symptoms of somatic illness to be falsely interpreted as psychopathology, somatic symptoms of depression and anxiety are omitted in the HADS. As some of the symptoms of anxiety and depression in diagnostic manuals are indeed of somatic character, this may have influenced the expected association between these variables and metabolic control in the current study. In fact, Bot et al. [16] reported that somatic symptoms of depression were some of the symptoms of depression most strongly associated with metabolic control, which may explain the lack of significant association between depression and metabolic control in this study. This assumption may be supported by another Norwegian study, which also used the HADS, and did not find a significant association between depression and HbA1c [23]. However, they did find a significant association between diabetes-related distress and metabolic control, supporting the suggested distinction between depression and diabetes-related distress as discussed above. Taken together, this suggests that various related correlates may play a role in explaining the relationship, or lack thereof, between depression/anxiety and metabolic control, and that illness-specific distress could be taken into account.

Participants scoring above cut-off for DEB and anxiety were significantly younger than participants scoring below cut-off. Similarly, patients with three positive screens (i.e. scored above cut-off for DEB, depression, and anxiety) were significantly younger than patients scoring below cut-off on all three measures of psychopathology. Decreasing eating disorder psychopathology by increasing age among adults is in line with previous eating disorder literature among individuals without T1D [40]. Similar to the negative correlation between 
eating disorder psychopathology and age, patients scoring above cut-off for anxiety were significantly younger than those scoring below. Previous literature has shown evidence of decreased susceptibility to both depression and anxiety with increasing age [10, 47]. This is only partially in conjunction to the current study, since the negative correlation between depression and age was not statistically significant.

The significant associations between age and measures of psychopathology are also evident in the correlation analyses (Table 4). Furthermore, and as expected, symptoms of DEB, depression, and anxiety were significantly associated with each other, with medium to large correlations. Finally, this study specifically aimed to inspect the relationships between eating disorder psychopathology with age and weight. As illustrated by Fig. 1, DEPS-R mean scores decreased by increasing age among females. This is in line with findings from the eating disorder literature among adults [40]. In contrast, eating disorder psychopathology has been found to increase by increasing age among adolescent samples [39]. These different age patterns most likely reflect the peak onset of eating disorders during the late adolescence [51]. Further, as demonstrated in Fig. 2, eating disorder psychopathology in the current study increased by increasing weight. This is consistent to previous research among adults in the eating disorder literature [40], as well as with adolescents with T1D [39].

The inclusion of males and older females represents a strength of this study as the majority of existing literature is focused on adolescent and young adult females only. Also, the use of the diabetes-specific measure DEPS-R is a strength and in line with current recommendations [5] to yield more accurate estimates of prevalence rates. However, the cross-sectional design is a weakness as we cannot infer causality. More studies are needed to elaborate on the directions of the relationships between diabetes and psychopathology. Also, data was collected from only one diabetes clinic, and we can therefore not be sure whether the results of this study are representative for the entire adult T1D population. Furthermore, the glycemic control was not measured at the same time as the psychological assessment. Finally, the data gathered in this study was self-reports only, and we can therefore not establish formal eating disorder diagnoses as defined by diagnostic manuals such as the DSM-5.

\section{Conclusion}

In conclusion, the present study points to the need for awareness of psychological comorbidity among patients with T1D. One fourth of females suffer from symptoms of anxiety and DEB, which is likely to negatively impact quality of life, a prioritized aim for diabetes treatment, regardless of metabolic control. Screening can be recommended to secure early detection and subsequent intervention, in particular among young adult females. Finally, the effects of age should be recognized, as older adolescent [39] and young adult females with T1D appear to be in particular risk of developing eating disorder psychopathology and symptoms of anxiety. This coincides with age of transitioning from pediatric to adult health care, which is generally described to be a vulnerable phase as discussed above. Such aspects point to the need for clinicians to be particularly aware of this age group in terms of eating disturbances.

\section{Abbreviations \\ BMI: Body mass index; CDC: The center for disease control and prevention; DEB: Disturbed eating behavior; DEPS-R: The diabetes eating problem survey - revised; DSM: The diagnostic and statistical manual of mental disorders; HADS: The hospital anxiety and depression scale; HADS-A: The hospital anxiety and depression scale; anxiety subscale; HADS-D: The hospital anxiety and depression scale; depression subscale; HbA1c: Hemoglobin A1c; HUNT: The Nord-Trøndelag health study; NDC: The Norwegian diabetic center; NOKLUS: The Norwegian quality improvement of laboratory examination; SPSS: The statistical package for the social sciences; T1D: Type 1 diabetes; T2D: Type 2 diabetes}

\section{Acknowledgements}

The authors would like to thank the staff at the Norwegian Diabetic Centre for their valuable contributions to the recruitment and data collection for this study. Also, we would like to thank the patients for their willingness to contribute to this study.

\section{Funding}

This study is funded by the Norwegian Health South-East Authority.

\section{Availability of data and materials}

The datasets used and/or analyzed during the current study are available from the corresponding author on reasonable request.

\section{Authors' contributions}

LW conceived the study, was responsible for recruitment of participants and data collection, analyzed the data, and wrote the manuscript. TS and KDJ contributed to the planning of the study, contributed with clinical data collection, and to the manuscript. ØR contributed to the planning of the study and to the manuscript. All authors read and approved the final manuscript.

\section{Ethics approval and consent to participate}

The Regional Committees for Medical and Health Research Ethics approved the study, and written consent was obtained from all participants.

\section{Consent for publication}

Not applicable

\section{Competing interests}

The authors declare that they have no competing interests.

\section{Publisher's Note}

Springer Nature remains neutral with regard to jurisdictional claims in published maps and institutional affiliations.

\section{Author details}

${ }^{1}$ Regional Department for Eating Disorders, Division of Mental Health and Addiction, Oslo University Hospital, P.O. Box 4956 Nydalen, N-0424 Oslo, Norway. ${ }^{2}$ Oslo Diabetes Research Centre, P.O. Box 4956 Nydalen, N-0424 Oslo, Norway. ${ }^{3}$ Department of Paediatric and Adolescent Medicine, Oslo University Hospital, P.O. Box 4956 Nydalen, N-0424 Oslo, Norway. ${ }^{4}$ Institute of Clinical Medicine, Faculty of Medicine, University of Oslo, Problemveien 7, N-0315 Oslo, Norway. ${ }^{5}$ The Norwegian Diabetic Centre, Sponhoggveien 19, 
N-0284 Oslo, Norway. ${ }^{6}$ Institute of Clinical Medicine, Mental Health and Addiction, University of Oslo, Problemveien 7, N-0315 Oslo, Norway.

\section{Received: 21 June 2018 Accepted: 27 July 2018 \\ Published online: 11 September 2018}

\section{References}

1. American Psychiatric Association. The Diagnostic and Statistical Manual of Mental Disorders: DSM-5. Fifth ed. Washington DC: American Psychiatric Association; 2013.

2. Olmsted MP, Colton PA, Daneman D, Rydall AC, Rodin GM. Prediction of the onset of disturbed eating behavior in adolescent girls with type 1 diabetes. Diabetes Care. 2008:31(10):1978-82.

3. Mannucci E, Rotella F, Ricca V, Moretti S, Placidi GF, Rotella CM. Eating disorders in patients with type 1 diabetes: a meta-analysis. J Endocrinol Invest. 2005;28(5):417-9.

4. Nielsen S. Eating disorders in females with type 1 diabetes: an update of a meta-analysis. Eur Eat Disord Rev. 2002;10(4):241-54.

5. Young V, Eiser C, Johnson B, Brierley S, Epton T, Elliott J, et al. Eating problems in adolescents with type 1 diabetes: a systematic review with meta-analysis. Diabet Med. 2012;30(2):189-98.

6. Weight gain associated with intensive therapy in the diabetes control and complications trial. The DCCT Research Group. Diabetes Care. 1988:11(7):567-73

7. Goebel-Fabbri AE, Fikkan J, Franko DL, Pearson K, Anderson BJ, Weinger K. Insulin restriction and associated morbidity and mortality in women with type 1 diabetes. Diabetes Care. 2008;31(3):415-9.

8. Nielsen S, Emborg C, Molbak AG. Mortality in concurrent type 1 diabetes and anorexia nervosa. Diabetes Care 2002:25(2):309-12.

9. Mangweth-Matzek B, Hoek HW. Epidemiology and treatment of eating disorders in men and women of middle and older age. Curr Opin Psychiatry. 2017;30(6):446-51.

10. de Groot M, Golden SH, Wagner J. Psychological conditions in adults with diabetes. Am Psychol. 2016;71(7):552-62.

11. Young-Hyman DL, Davis CL. Disordered eating behavior in individuals with diabetes: importance of context, evaluation, and classification. Diabetes Care. 2010;33(3):683-9.

12. Hudson Jl, Hiripi E, Pope HG Jr, Kessler RC. The prevalence and correlates of eating disorders in the National Comorbidity Survey Replication. Biol Psychiatry. 2007;61(3):348-58

13. Anderson RJ, Freedland KE, Clouse RE, Lustman PJ. The prevalence of comorbid depression in adults with diabetes: a meta-analysis. Diabetes Care. 2001;24(6):1069-78.

14. Smith KJ, Beland M, Clyde M, Gariepy G, Page V, Badawi G, et al. Association of diabetes with anxiety: a systematic review and meta-analysis. J Psychosom Res. 2013;74(2):89-99.

15. Bernstein CM, Stockwell MS, Gallagher MP, Rosenthal SL, Soren K. Mental health issues in adolescents and young adults with type 1 diabetes: prevalence and impact on glycemic control. ClinPediatr(Phila). 2013:52(1):10-5.

16. Bot M, Pouwer F, de Jonge P, Tack CJ, Geelhoed-Duijvestijn PH, Snoek FJ. Differential associations between depressive symptoms and glycaemic control in outpatients with diabetes. Diabet Med. 2013:30(3):e115-22.

17. Hislop AL, Fegan PG, Schlaeppi MJ, Duck M, Yeap BB. Prevalence and associations of psychological distress in young adults with type 1 diabetes. Diabet Med. 2008;25(1):91-6

18. Lustman PJ, Anderson RJ, Freedland KE, de Groot M, Carney RM, Clouse RE Depression and poor glycemic control: a meta-analytic review of the literature. Diabetes Care. 2000:23(7):934-42.

19. van Bastelaar KM, Pouwer F, Geelhoed-Duijvestijn PH, Tack CJ, Bazelmans E, Beekman AT, et al. Diabetes-specific emotional distress mediates the association between depressive symptoms and glycaemic control in type and type 2 diabetes. Diabet Med. 2010;27(7):798-803.

20. Hessler DM, Fisher L, Polonsky WH, Masharani U, Strycker LA, Peters AL, et al. Diabetes distress is linked with worsening diabetes management over time in adults with type 1 diabetes. Diabet Med. 2017:34(9):1228-34

21. Schmitt A, Reimer A, Kulzer B, Haak T, Gahr A, Hermanns N. Negative association between depression and diabetes control only when accompanied by diabetes-specific distress. J Behav Med. 2015;38(3):556-64

22. Shaban C, Fosbury JA, Cavan DA, Kerr D, Skinner TC. The relationship between generic and diabetes specific psychological factors and glycaemic control in adults with type 1 diabetes. Diabetes Res Clin Pract. 2009:85(3):e26-9.

23. Strandberg RB, Graue M, Wentzel-Larsen T, Peyrot M, Rokne B. Relationships of diabetes-specific emotional distress, depression, anxiety, and overall wellbeing with $\mathrm{HbA1c}$ in adult persons with type 1 diabetes. J Psychosom Res. 2014;77(3):174-9.

24. Markowitz JT, Butler DA, Volkening LK, Antisdel JE, Anderson BJ, Laffel LM. Brief screening tool for disordered eating in diabetes: internal consistency and external validity in a contemporary sample of pediatric patients with type 1 diabetes. Diabetes Care. 2010;33(3):495-500.

25. Wisting $L$, Froisland DH, Skrivarhaug $T$, Dahl-Jorgensen $K$, Ro O. Psychometric properties, norms, and factor structure of the diabetes eating problem survey-revised in a large sample of children and adolescents with type 1 diabetes. Diabetes Care. 2013;36(8):2198-202.

26. Zigmond AS, Snaith RP. The hospital anxiety and depression scale. Acta Psychiatr Scand. 1983;67(6):361-70.

27. Leiknes KA, Dalsbø TK, Siqveland J. Måleegenskaper ved den norske versjonen av Hospital Anxiety and Depression Scale (HADS). 2016.

28. World Health Organization. BMI classification 2012

29. Centers for Disease Control and Prevention (CDC). Web-based Injury Statistics Query and Reporting System (WISQARS).http://www.cdc.gov/ injury/wisqars/index.html [.

30. Ballard J, Crane DR. Eating disorders treatment patterns by age. Eat Disord. 2015;23(3):262-74

31. American Diabetes A. Standards of medical Care in Diabetes-2017 abridged for primary care providers. Clin Diabetes. 2017;35(1):5-26.

32. Cohen J. Statistical Power Analysis for the Behavioural Sciences. 2 Ed. Hillsdale; 1988.

33. IBM SPSS Statistics for Windows, Version 23. Version 23 ed: Armonk, NY: IBM Corp; 2015.

34. Bachle C, Stahl-Pehe A, Rosenbauer J. Disordered eating and insulin restriction in youths receiving intensified insulin treatment: results from a nationwide population-based study. Int J Eat Disord. 2016;49(2):191-6.

35. d'Emden H, McDermott B, D'Silva N, Dover T, Ewais T, Gibbons K, et al. Psychosocial screening and management of young people aged 18-25 years with diabetes. Intern Med J. 2017;47(4):415-23.

36. Jacobi C, Hayward C, de Zwaan M, Kraemer HC, Agras WS. Coming to terms with risk factors for eating disorders: application of risk terminology and suggestions for a general taxonomy. Psychol Bull. 2004;130(1):19-65.

37. Atik Altinok Y, Ozgur S, Meseri R, Ozen S, Darcan S, Goksen D. Reliaability and validity of the diabetes eating problem survey-revised on Turkish children and adolescents with type 1 diabetes mellitus. J Clin Res Pediatr Endocrinol. 2017:9(4):323-328.

38. Markowitz JT, Alleyn CA, Phillips R, Muir A, Young-Hyman D, Laffel LM. Disordered eating behaviors in youth with type 1 diabetes: prospective pilot assessment following initiation of insulin pump therapy. Diabetes Technol Ther. 2013;15(5):428-33.

39. Wisting L, Froisland DH, Skrivarhaug T, Dahl-Jorgensen K, Ro O. Disturbed eating behavior and omission of insulin in adolescents receiving intensified insulin treatment: a nationwide population-based study. Diabetes Care. 2013:36(11):3382-7.

40. Ro $\mathrm{O}$, Reas $\mathrm{DL}$, Rosenvinge J. The impact of age and $\mathrm{BMI}$ on eating disorder examination questionnaire (EDE-O) scores in a community sample. Eat Behav. 2012;13(2):158-61.

41. Hilliard ME, Perlus JG, Clark LM, Haynie DL, Plotnick LP, Guttmann-Bauman I, et al. Perspectives from before and after the pediatric to adult care transition: a mixed-methods study in type 1 diabetes. Diabetes Care. 2014; 37(2):346-54.

42. Lotstein DS, Seid M, Klingensmith G, Case D, Lawrence JM, Pihoker C, et al. Transition from pediatric to adult care for youth diagnosed with type 1 diabetes in adolescence. Pediatrics. 2013;131(4):e1062-70.

43. Lyons SK, Becker DJ, Helgeson VS. Transfer from pediatric to adult health care: effects on diabetes outcomes. Pediatr Diabetes. 2014;15(1):10-7.

44. Lloyd CE, Dyer PH, Barnett AH. Prevalence of symptoms of depression and anxiety in a diabetes clinic population. Diabet Med. 2000;17(3):198-202.

45. Bjelland I, Lie SA, Dahl AA, Mykletun A, Stordal E, Kraemer HC. A dimensional versus a categorical approach to diagnosis: anxiety and depression in the HUNT 2 study, Int J Methods Psychiatr Res. 2009:18(2):128-37.

46. Knychala MA, Jorge ML, Muniz CK, Faria PN, Jorge PT. High-risk alcohol use and anxiety and depression symptoms in adolescents and adults with type 1 diabetes mellitus: a cross-sectional study. Diabetol Metab Syndr. 2015;7:24. 
47. Roy T, Lloyd CE. Epidemiology of depression and diabetes: a systematic review. J Affect Disord 2012;142 Suppl:S8-21.

48. Bachle C, Lange K, Stahl-Pehe A, Castillo K, Scheuing N, Holl RW, et al. Symptoms of eating disorders and depression in emerging adults with early-onset, long-duration type 1 diabetes and their association with metabolic control. PLoS One. 2015;10(6):e0131027.

49. Snoek FJ, Bremmer MA, Hermanns N. Constructs of depression and distress in diabetes: time for an appraisal. Lancet Diabetes Endocrinol. 2015;3(6):450-60.

50. Fisher L, Gonzalez JS, Polonsky WH. The confusing tale of depression and distress in patients with diabetes: a call for greater clarity and precision. Diabet Med. 2014;31(7):764-72.

51. Bryant-Waugh R, Lask B. Overview of the eating disorders. In: Lask B, BryantWaugh R, editors. Eating disorders in childhood and adolescence. 3rd ed. London and New York: Routledge; 2007. p. 35-50.

Ready to submit your research? Choose BMC and benefit from:

- fast, convenient online submission

- thorough peer review by experienced researchers in your field

- rapid publication on acceptance

- support for research data, including large and complex data types

- gold Open Access which fosters wider collaboration and increased citations

- maximum visibility for your research: over $100 \mathrm{M}$ website views per year

At BMC, research is always in progress.

Learn more biomedcentral.com/submissions 